\title{
Effects of hydrothermal treatment on the properties of nanoapatite crystals
}

This article was published in the following Dove Press journal:

International Journal of Nanomedicine

27 September 2012

Number of times this article has been viewed

\author{
Wei Liangl,* \\ Yunfei $\mathrm{Niu}^{2, *}$ \\ Shuhua $\mathrm{Ge}^{1}$ \\ Shaojun Song ${ }^{2}$ \\ Jiacan $\mathrm{Su}^{2}$ \\ Zhuojing Luo' \\ 'Department of Orthopedics, Xijing \\ Hospital, Fourth Military Medical \\ University, Xi'an, Shaanxi, People's \\ Republic of China; ${ }^{2}$ Department of \\ Orthopedics, Changhai Hospital, \\ Second Military Medical University, \\ Shanghai, People's Republic of China \\ *These authors contributed equally to \\ this work
}

Correspondence: Jiacan Su Department of Orthopedics, Changhai Hospital, Second Military

Medical University, Shanghai,

People's Republic of China

Tel +862181873400

Fax +862181873398

Email sujiacan2012@yahoo.cn
Abstract: We report the synthesis of nanoapatite crystals via a hydrothermal reaction of hydroxyapatite precipitates. The impact of the reaction conditions on the properties of the crystals obtained were evaluated. The hydrothermal reaction that takes place markedly affected the crystallinity, morphology, and size of the nanoapatite crystals formed. High crystallinity and large crystal size were obtained at higher hydrothermal temperatures and longer hydrothermal reaction times. The nanoapatite crystals were needle-like when prepared under ambient pressure conditions and rod-like when prepared under increased pressure. The crystals prepared at ambient pressure had a larger aspect ratio compared with those prepared under increased pressure. The aging time of the initial hydroxyapatite precipitate significantly affected growth of the nanoapatite crystals. With other hydrothermal reaction conditions being equal, the fresh hydroxyapatite precipitate produced notably larger crystals than the aged hydroxyapatite precipitate. The influence of apatite morphology on osteoblast viability was studied by MTT assay. The results indicate that the rod-like apatite showed a better biological response than needle-like apatite in promoting cell growth. Transmission electron microscopy showed that large quantities of needle apatite entered into cells and damaged their morphology.

Keywords: nanoapatite crystals, hydrothermal treatment, morphology, cell viability

\section{Introduction}

Natural bone consists mainly of organic collagen and inorganic minerals. Minerals account for $60 \%$ of the composition of bone and mainly exist in the form of nanoapatite crystals. ${ }^{1-3}$ The apatite crystals in human bone have different sizes and morphologies in different body parts and among people of different ages. ${ }^{4,5}$ Synthetic nanoscale apatite crystals have been prepared by mimicking the apatite crystals in natural bone. ${ }^{6}$ Nevertheless, the synthetic nanoscale apatite crystals formed show variable size and morphology according to the synthetic methods, synthesis conditions, and reaction precursors used. ${ }^{7}$ It has been reported that diammonium phosphate and calcium nitrate can be reacted to form hydroxyapatite precipitates, which can then undergo hydrothermal reaction at $140^{\circ} \mathrm{C}$ and $0.3 \mathrm{MPa}$ for 2 hours to form $20 \mathrm{~nm} \times 90 \mathrm{~nm}$ nanorod crystals. $^{8,9}$

This paper reports a novel and simple method by which to synthesize nanoscale calcium-deficient apatite precipitates. By using dimethylacetamide as the solvent and dispersant for nanoapatite synthesis, a dimethylacetamide solution of calcium nitrate was able to be reacted with an aqueous solution of sodium phosphate to give a hydroxyapatite precipitate. ${ }^{10}$ Subsequently, nanoscale calcium-deficient apatite crystals were prepared using hydrothermal treatment. ${ }^{11}$ The aim of the present study was 
to clarify how different hydrothermal conditions affect the crystallinity, size, and morphology of synthesized nanoscale calcium-deficient apatite crystals.

There are some reports on nanosize hydroxyapatite and its biological effects. ${ }^{11}$ One study reported that sphere-like hydroxyapatite $20 \mathrm{~nm}$ in diameter has better effects in terms of promoting cell growth and inhibiting apoptosis than ones with a diameter of $80 \mathrm{~nm} .{ }^{12}$ Moreover, rod-like nanoapatite particles $20-30 \mathrm{~nm}$ in width and $50-80 \mathrm{~nm}$ in length support attachment and growth of human osteoblast-like cells. ${ }^{13}$ However, there has been a lack of studies focusing on the biological properties of rod-like and needle-like apatite.

Therefore, in this study, a hydrothermal synthesis method was used to prepare two types of apatite with different morphology, ie, rod-like and needle-like apatite. The response of bone-forming osteoblast cells to nanoapatite was also investigated in order to monitor the conditions in which the apatite was in contact or reacting with the surrounding biological environment. The biological properties of rod-like and needle-like nanoapatite were assessed in an osteoblastlike MG-63 model.

\section{Materials and methods}

Calcium nitrate (analytical grade, purchased from Sinopharm Chemical Reagent Co, Ltd, Shanghai, China) was added to dimethylacetamide (analytical grade, Sinopharm Chemical Reagent Co, Ltd) under stirring to prepare solution A. Sodium phosphate (analytical grade, Sinopharm Chemical Reagent Co, Ltd) was dissolved in deionized water (purchased from Shkys Water and Wastewater Treatment Co, Ltd, Shanghai, China) to prepare solution B. Solution B was heated to $70^{\circ} \mathrm{C}$ and solution $\mathrm{A}$ was added dropwise with stirring. After the addition was complete, the mixture was stirred for a further 2 hours at $70^{\circ} \mathrm{C}$, allowed to stand for 24 hours at room temperature, and then centrifuged. The supernatant was removed and the residue was washed with deionized water three times to give a slurry of apatite precipitate. A portion of the slurry was collected and aged for 24 hours or 2 months, after which the apatite slurry was hydrothermally treated in a glass tube at $140^{\circ} \mathrm{C}$ in an autoclave, as outlined in Table 1.

The crude apatite precipitate slurry and the hydrothermally processed slurries were submitted to transmission electron microscopy (TEM, H-600; Hitachi, Tokyo, Japan) and X-ray diffraction analysis (DX-2500; Dandong Fangyuan Instrument Co, Ltd, Liaoning, China) to determine the morphology of the apatite crystals. The nanoapatite crystals formed by treatment $\mathrm{D}\left(100^{\circ} \mathrm{C}\right.$, ambient pressure, hydrothermal treatment for 4 hours) were submitted to Fourier transform
Table I Portion of apatite slurry hydrothermally treated under different conditions

\begin{tabular}{lllll}
\hline n & Aging & Temperature & Pressure & $\begin{array}{l}\text { Hydrothermal } \\
\text { treatment }\end{array}$ \\
\hline A & 24 hours & $70^{\circ} \mathrm{C}$ & Ambient & 2 hours \\
B & 24 hours & $70^{\circ} \mathrm{C}$ & Ambient & 4 hours \\
C & 24 hours & $100^{\circ} \mathrm{C}$ & Ambient & 2 hours \\
D & 24 hours & $100^{\circ} \mathrm{C}$ & Ambient & 4 hours \\
E & 24 hours & $140^{\circ} \mathrm{C}$ & $0.3 \mathrm{MPa}$ & 2 hours \\
F & 2 months & $100^{\circ} \mathrm{C}$ & Ambient & 4 hours \\
G & 2 months & $140^{\circ} \mathrm{C}$ & $0.3 \mathrm{MPa}$ & 2 hours \\
H & 0 & $70^{\circ} \mathrm{C}$ & Ambient & 0 \\
\hline
\end{tabular}

infrared spectroscopy (Spectrum ${ }^{\mathrm{TM}}$ One, Perkin-Elmer, Boston, MA), and were analyzed by infrared spectroscopy again after sintering at $600^{\circ} \mathrm{C}$ and $800^{\circ} \mathrm{C}$, respectively.

The viability of MG-63 was assessed using MTT (3-(4,5dimethylthiazol-2-yl)- 2,5-diphenyl tetrazolium bromide) assay. MG-63 cells were seeded at a density of $0.5 \times 10^{4}$ per well in 96-well plates. Twenty-four hours after seeding, the cells were rinsed with phosphate-buffered saline, and $200 \mu \mathrm{L}$ of rod-like or needle-like apatite solution with an apatite content of $5 \mathrm{~g} / \mathrm{mL}$ (or $200 \mu \mathrm{L}$ of medium only as the control) was added to the cells. After incubating the cells in a humidified atmosphere with $5 \% \mathrm{CO}_{2}$ at $37^{\circ} \mathrm{C}$ for one, 3 , and 5 days, the sample solutions were removed, and MTT was then added at a concentration of $0.5 \mathrm{mg} / \mathrm{mL}$ in medium for 4 hours at $37^{\circ} \mathrm{C}$. At the end of the assay, the blue formazan reaction product was dissolved by adding $100 \mu \mathrm{L}$ of $10 \%$ sodium dodecyl sulfate $/ 0.01 \mathrm{M} \mathrm{HCl}$ to each well. The absorbance value was measured at $570 \mathrm{~nm}$ using a microplate reader (Bio-Rad Model 680; Bio-Rad, Hercules, CA). Six specimens were tested for each incubation period, and each test was performed in triplicate. The results are reported as units of optical density.

TEM was used to observe the intracellular internalization and localization of nanoapatite further. MG-63 cells were plated into $60 \mathrm{~mm}^{2}$ polystyrene dishes at a density of $5 \times 10^{5}$ cells $/ \mathrm{mL}$ and allowed to attach for 24 hours. The cells were exposed to the different apatite slurries. After 3 days, the monolayers of cells were rinsed with phosphate-buffered saline and fixed in $2 \%$ paraformaldehyde with $2.5 \%$ glutaraldehyde at $4^{\circ} \mathrm{C}$ for 2 hours. The fixed cells were rinsed three times in sodium phosphate buffer, osmicated by incubation for one hour in $1 \%$ osmium tetroxide with $1.25 \%$ potassium ferrocyanide with $0.15 \mathrm{M}$ sodium phosphate buffer. The cells were rinsed four times in water, dehydrated using increasing concentrations of ethanol $(30 \%, 50 \%, 75 \%, 100 \%$, 10 minutes each), and embedded in epoxy resin. Thin sections 
(around $70 \mathrm{~nm}$ ) were cut using a diamond knife, collected on 200 mesh copper grids, and stained with 4\% aqueous uranylacetate (Polysciences Inc, Warrington, PA) for 15 minutes, followed by Reynolds' lead citrate for 7 minutes. Specimens were observed using TEM.

\section{Statistical analysis}

Quantitative data are expressed as the mean \pm the standard deviation. Differences between groups were determined by analysis of variance. The level of statistical significance was defined as $P<0.05$.

\section{Results}

\section{X-ray diffraction analysis}

It can be seen from Figure 1A that the crude apatite precipitates had very low crystallinity and only a very weak crystalline peak in the (002) plane. In contrast, the hydrothermally treated nanoapatite crystals show improved crystallinity (Figure $1 \mathrm{~B}$ and $\mathrm{C}$ ) and characteristic peaks at $2 \theta=26^{\circ}, 32^{\circ}, 34^{\circ}, 40^{\circ}, 47^{\circ}$ and $50^{\circ}$. This is due to growth of the apatite crystals during the hydrothermal reaction, and the crystallinity increased with longer hydrothermal reaction times.

Figure 2 shows the X-ray diffraction spectra for apatite slurry after hydrothermal treatment at $100^{\circ} \mathrm{C}$. It can be seen that a longer hydrothermal reaction time $[2$ hours for (A) and 4 hours for (B)] induces higher crystallinity. Increasing the hydrothermal reaction temperature from $70^{\circ} \mathrm{C}$ (Figure 1) to $100^{\circ} \mathrm{C}$ (Figure 2) clearly increased the crystallinity,

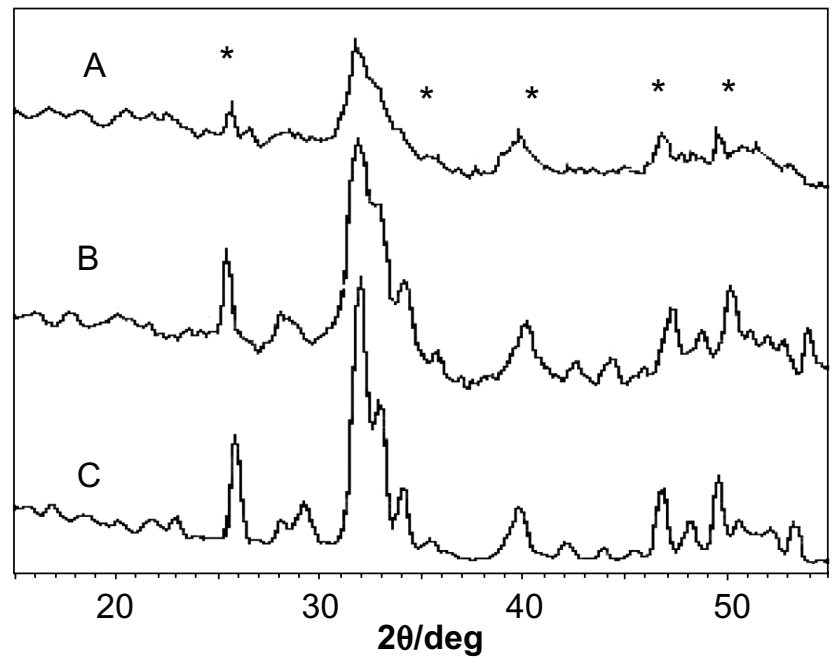

Figure I X-ray diffraction spectra of (A) fresh nanoapatite precipitate, (B) nanoapatite prepared from hydrothermal reaction at $70^{\circ} \mathrm{C}$ and ambient pressure for 2 hours, and (C) nanoapatite prepared from hydrothermal reaction at $70^{\circ} \mathrm{C}$ and ambient pressure for 4 hours.

Notes: No aging in any cases. *Represents apatite peaks.

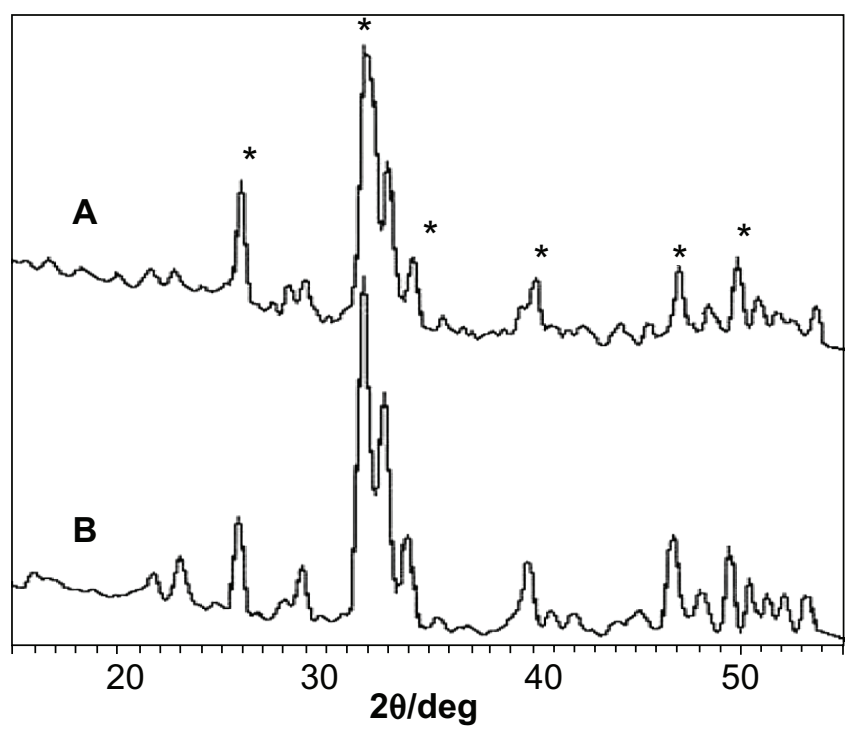

Figure 2 X-ray diffraction spectra of nanoapatite prepared from (A) hydrothermal reaction at $100^{\circ} \mathrm{C}$ and ambient pressure for 2 hours and $(B)$ hydrothermal reaction at $100^{\circ} \mathrm{C}$ and ambient pressure for 4 hours.

Notes: No aging in any cases. *Represents apatite peaks.

indicating that higher temperature of the hydrothermal treatment promotes apatite crystallinity. The highest crystallinity is observed in Figure 3 where the slurry was treated at $140^{\circ} \mathrm{C}$ and $0.3 \mathrm{MPa}$ for 2 hours. It can be concluded that apatite crystallinity increases with increasing temperature and reaction time of the hydrothermal reaction.

\section{Infrared analysis}

It can be seen from Figure 4 that the peaks at $3570 \mathrm{~cm}^{-1}$ and $630 \mathrm{~cm}^{-1}$ are characteristic of hydroxyl $(-\mathrm{OH})$ groups in nanoapatite crystals. The peaks at $1638 \mathrm{~cm}^{-1}$ and the broad peak from $3700 \mathrm{~cm}^{-1}$ to $3000 \mathrm{~cm}^{-1}$ are the water peaks. The peak at $871 \mathrm{~cm}^{-1}$ is attributable to $\mathrm{HPO}_{4}{ }^{2-}$, the peaks at $1456 \mathrm{~cm}^{-1}$ and $1413 \mathrm{~cm}^{-1}$ are characteristic of $\mathrm{CO}_{3}{ }^{2-}$, and the

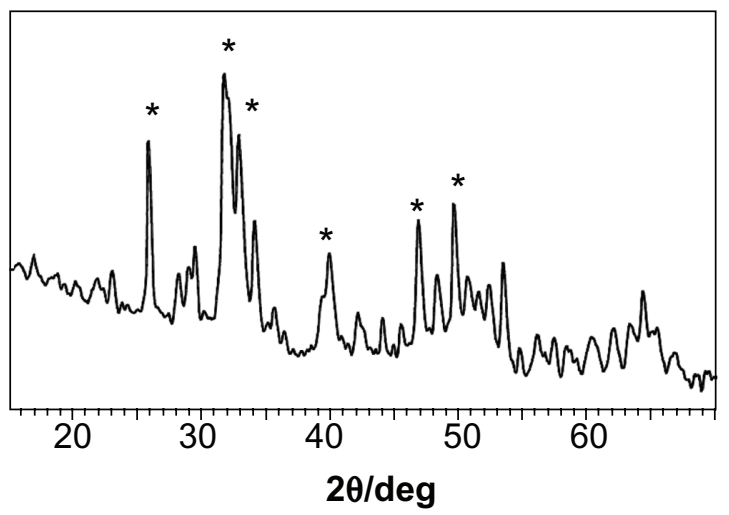

Figure $3 \mathrm{X}$-ray diffraction spectrum of nanoapatite crystal prepared from hydrothermal reaction at $140^{\circ} \mathrm{C}$ and $0.3 \mathrm{MPa}$ for 2 hours using fresh initial precipitate. Note: *Represents apatite peaks. 


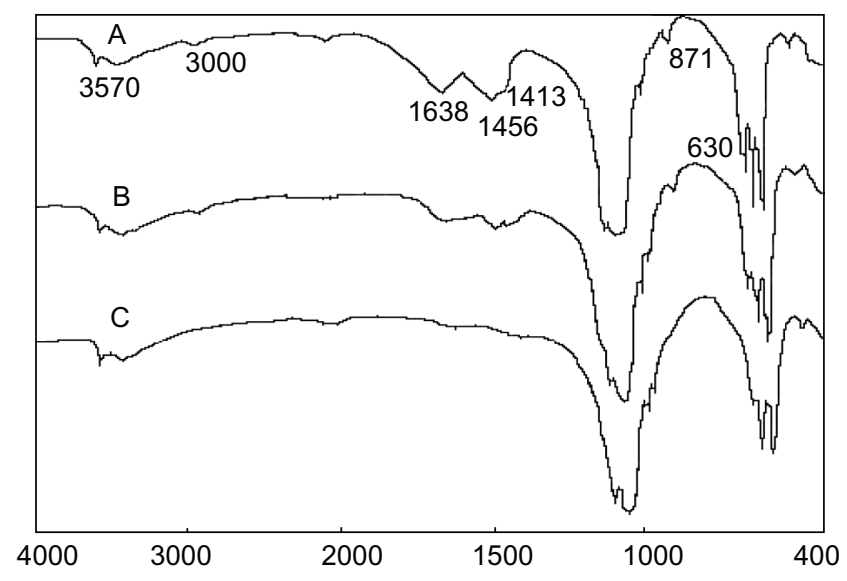

Figure 4 Infrared spectra of apatite crystals (A) hydrothermally treated at $100^{\circ} \mathrm{C}$, (B) sintered at $600^{\circ} \mathrm{C}$, and (C) sintered at $800^{\circ} \mathrm{C}$.

peaks at $1038 \mathrm{~cm}^{-1}$ and $564 \mathrm{~cm}^{-1}$ are due to the phosphate ion. The results indicate that species such as $\mathrm{CO}_{3}{ }^{2-}, \mathrm{HPO}_{4}{ }^{2-}$, $\mathrm{H}_{2} \mathrm{O}, \mathrm{OH}^{-}$, and $\mathrm{PO}_{4}^{3-}$ exist in nanoapatite crystals. Note that the water peak is reduced after sintering the apatite crystal at $600^{\circ} \mathrm{C}$ for 2 hours (Figure 4B), and the water peak at $1638 \mathrm{~cm}^{-1}$ basically disappeared after sintering the apatite crystal at $800^{\circ} \mathrm{C}$ for 2 hours (Figure $4 \mathrm{C}$ ). In addition, the $\mathrm{CO}_{3}{ }^{2-}$ and $\mathrm{HPO}_{4}{ }^{2-}$ peaks remained after sintering at $600^{\circ} \mathrm{C}$ but disappeared after sintering at $800^{\circ} \mathrm{C}$, suggesting that these species decompose at $600^{\circ} \mathrm{C}-800^{\circ} \mathrm{C}$.

\section{TEM analysis}

It can be seen from Figure 5 that the crude apatite had low crystallinity. The nanoapatite has a very small size of about $5 \mathrm{~nm} \times 35 \mathrm{~nm}$ and exhibits a needle shape, according to the statistical analysis. It can be seen from Figure 6 that after hydrothermal reaction at $70^{\circ} \mathrm{C}$ for 2 hours and 4 hours, the crystallinity of the nanoapatite increased and

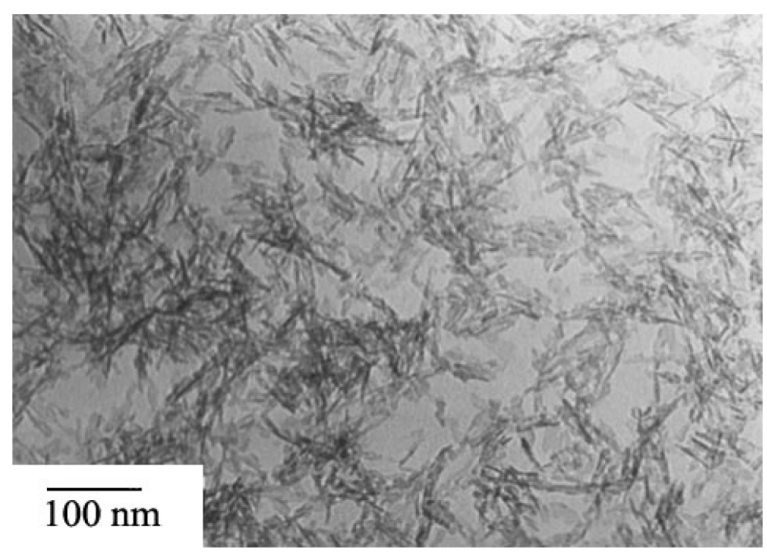

Figure 5 Transmission electron micrographs of nanoapatite without hydrothermal treatment. the size also increased to $10-20 \mathrm{~nm} \times 70-80 \mathrm{~nm}$. The size of the crystal prepared by 4 hours of reaction was larger than that after 2 hours of reaction, indicating that prolonging the hydrothermal reaction time is beneficial to apatite crystal growth.

It can be seen from Figure 7 that after hydrothermal reaction at ambient pressure at $100^{\circ} \mathrm{C}$ for 2 hours and 4 hours, the size of the apatite formed was about $20 \mathrm{~nm} \times 80 \mathrm{~nm}$. Combining this with the results shown in Figure 6, it can be seen that both increasing the reaction temperature to $100^{\circ} \mathrm{C}$ and extending the reaction time to 4 hours promotes apatite crystal growth. The apatite crystals prepared at $70^{\circ} \mathrm{C}$ and $100^{\circ} \mathrm{C}$ were all needle-like.

It can be seen from Figure 8 that the apatite crystal prepared without aging is of larger size than that prepared after the precipitate slurry had been aged for 2 months. Therefore, the aging time of the hydroxyapatite precipitate impacts nanoapatite crystal growth in the hydrothermal reaction, and the newly prepared precipitate should be immediately subjected to hydrothermal reaction so that the apatite crystals can grow larger.

Figure 9A shows nanoapatite crystals prepared by hydrothermal reaction of fresh apatite precipitate at $140^{\circ} \mathrm{C}$ and 0.3 MPa. Figure 9B shows the nanoapatite crystals prepared by hydrothermal reaction at $140^{\circ} \mathrm{C}$ and $0.3 \mathrm{MPa}$ from apatite precipitate that had been aged for 2 months. It can be seen that the apatite crystals prepared under increased pressure all have a rod-like shape. The crystal size in Figure 9A is larger than that in Figure 9B, indicating that larger crystals can be prepared from the fresh hydroxyapatite precipitate by hydrothermal reaction than from the aged precipitate.

On comparison, it can be noted that the apatite crystals prepared under ambient pressure are needle-like (Figure 8) and those prepared at $0.3 \mathrm{MPa}$ are rod-like (Figure 9). Further, the apatite crystals prepared under ambient pressure appear to have a larger aspect ratio.

\section{Cell viability}

Figure 10 shows that the optical density value increased with time when MG-63 cells were cocultured with needle-like and rod-like apatite, indicating that needle apatite affected cell proliferation. Clearly, both needle-like and rod-like apatite had the ability to improve the viability of osteoblasts. After 5 days, the optical density value of rod-like apatite was significantly higher than that of needle-like apatite and controls $(P<0.05)$. This suggested that rod-like apatite could promote the viability of MG-63 cells. 

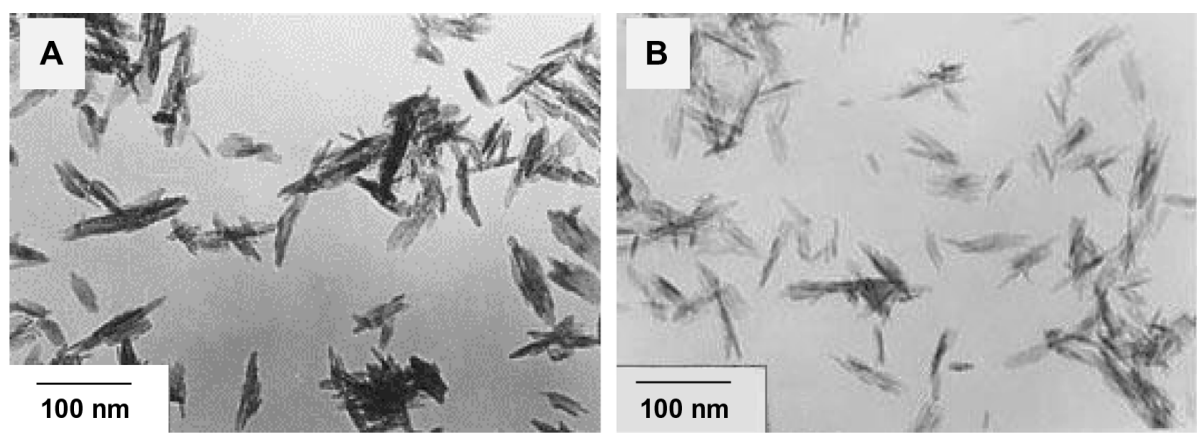

Figure 6 Transmission electron micrographs of nanoapatite prepared from hydrothermal reaction at $70^{\circ} \mathrm{C}$ under ambient pressure (A) for 2 hours and (B) for 4 hours.
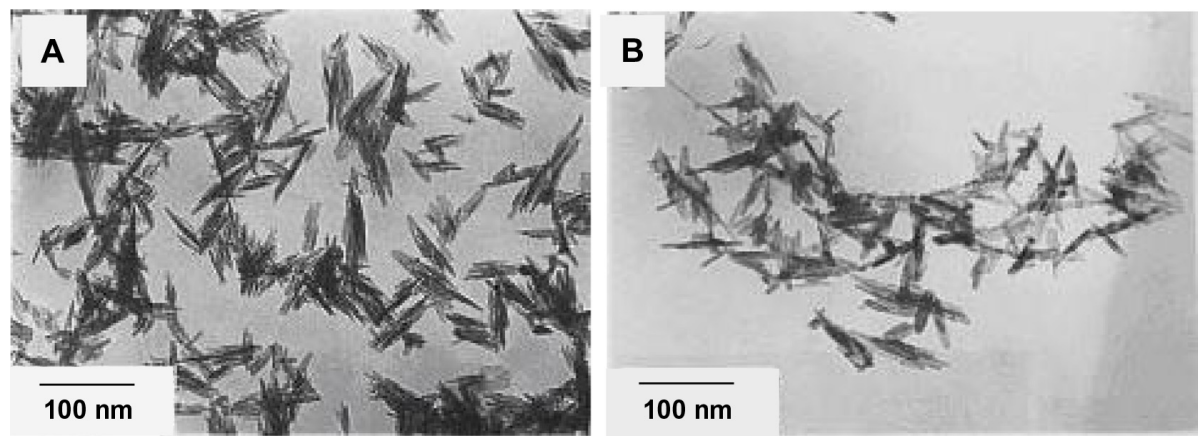

Figure 7 Transmission electron micrographs of nanoapatite prepared from hydrothermal reaction at $100^{\circ} \mathrm{C}$ under ambient pressure (A) for 2 hours and (B) for 4 hours.
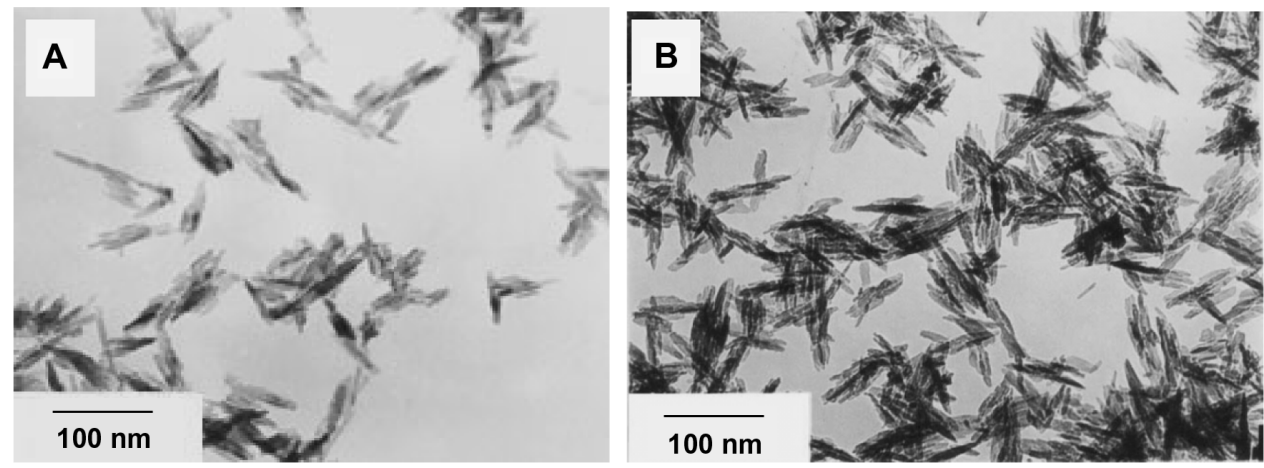

Figure 8 Transmission electron micrographs of nanoapatite prepared from hydrothermal reaction at $100^{\circ} \mathrm{C}$ under ambient pressure (A) using fresh precipitate and (B) using aged precipitate.
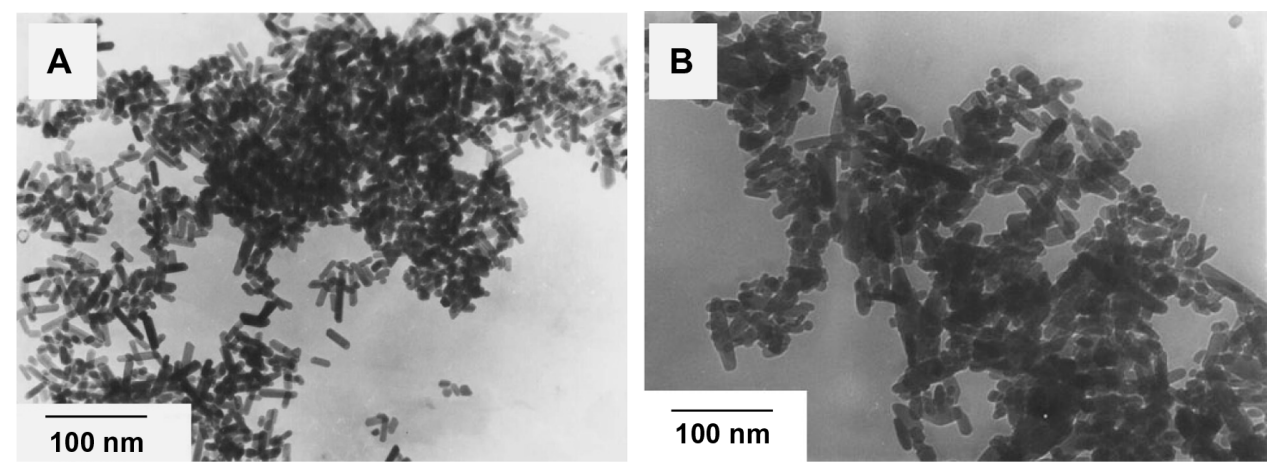

Figure 9 Transmission electron micrographs of nanoapatite crystals prepared from 2 hours of hydrothermal reaction at $140^{\circ} \mathrm{C}$ and $0.3 \mathrm{MPa}$ using $(\mathbf{A})$ fresh precipitate and (B) aged precipitate. 


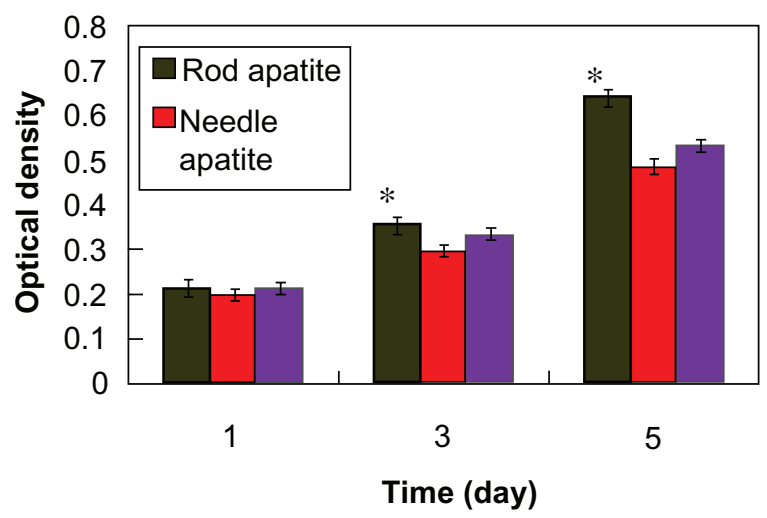

Figure 10 Viability of osteoblast cells responding to different apatite crystals at various time points by MTT analysis.

Note: $* P<0.05$ compared with control.

\section{Interaction of nanoapatite with MG-63 cells}

On TEM images, MG-63 cells in rod-like apatite showed a typical ultrastructure characterized by a well preserved plasma membrane, a nucleus with uniformly dispersed chromatin, and a clear nucleolus, and a cytoplasm containing randomly distributed organelles and electron-dense crystals, as shown in Figure 11A. However, for cells in needle-like apatite, morphology changes such as swollen mitochondria, a deformed nucleus, and condensed chromatin were observed, as shown in Figure 11B.

The TEM images showed that apatite dissolved as a function of time within MG-63 cells. The dissolution of need-like apatite occurred progressively within lysosomes, as shown in Figure 12. After initial uptake into the phagolysosome, rodlike apatite became more densely packed and a proportion of the crystals started to dissolve, as shown in Figure 12A, while needle-like apatite became dispersed (Figure 12C).

\section{Discussion}

Apatite crystals synthesized at room temperature are small nanoparticles with low crystallinity, which makes liquid-solid separation very difficult when rinsing with deionized water, and the crystal morphology is obscured under TEM. As a result, nanoapatite precipitates are usually prepared at $70^{\circ} \mathrm{C}$. Nanoapatite precipitates prepared at $70^{\circ} \mathrm{C}$ already have a certain degree of crystallinity that is readily visible under TEM. Subsequently, hydrothermal reaction enables the nanoapatite crystal to grow into a certain shape.

The duration of the hydrothermal reaction affects the size and morphology of nanoapatite crystals, because the crystals grow larger with prolonged reaction times. Prolonging the hydrothermal treatment time promotes solvent evaporation and maintains the solution in a supersaturation state, thereby assisting crystal growth.

The duration and temperature of the hydrothermal reaction has a significant impact on the crystallinity of the nanoapatite formed. The nanoapatite crystallinity becomes greater at higher hydrothermal reaction temperatures and longer reaction times. Freshly prepared apatite has low crystallinity and is abundant in amorphous form, but already exhibits preferential growth along the $\mathrm{C}$ axis. ${ }^{6}$ During the hydrothermal reaction, the apatite crystallizes rapidly along the $\mathrm{C}$ axis and crystallinity increases as a result. ${ }^{14}$

A high hydrothermal treatment temperature can assist apatite crystal growth because a high temperature can provide a highly active surface for the small apatite precipitate particles to bind to each other on the $\mathrm{C}$ axis and grow into larger needles. ${ }^{7} 15$ Before hydrothermal treatment, the precipitates already show preferential growth along the $\mathrm{C}$ axis, so the particle growth along the $\mathrm{C}$ axis is much faster than in the horizontal direction. ${ }^{6,16}$

TEM analysis shows that the nanoapatite crystals synthesized at ambient pressure were needle-like whereas those prepared under increased pressure were rod-like. The biological apatite crystals in human bone are needle-like, indicating that the nanoapatite crystals synthesized at ambient pressure more closely resemble the biological apatite crystals in human bone. ${ }^{17}$ Under high pressure, the formation
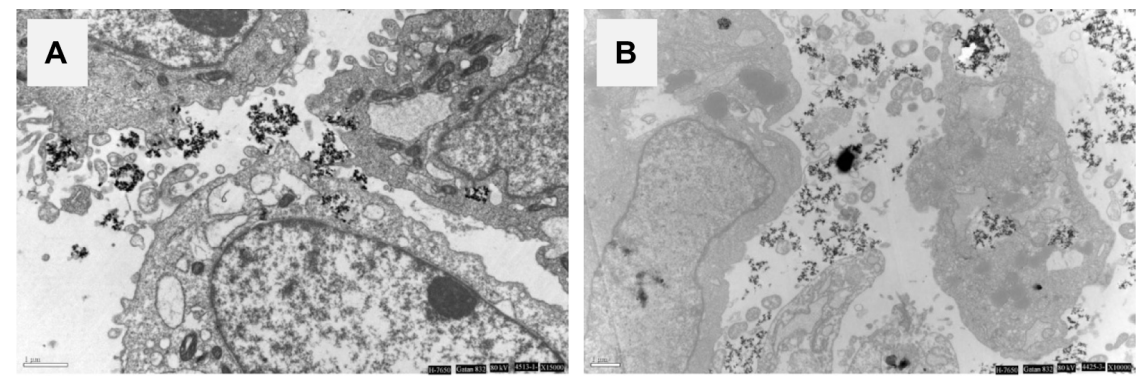

Figure II Transmission electron micrographs of MG-63 cells exposed to rod-like apatite and needle-like apatite for 3 days. (A) Rod apatite is close to the nuclear envelope, but does not enter into the cell nucleus. (B) Needle-like apatite leads to changes in the nucleus morphology. 

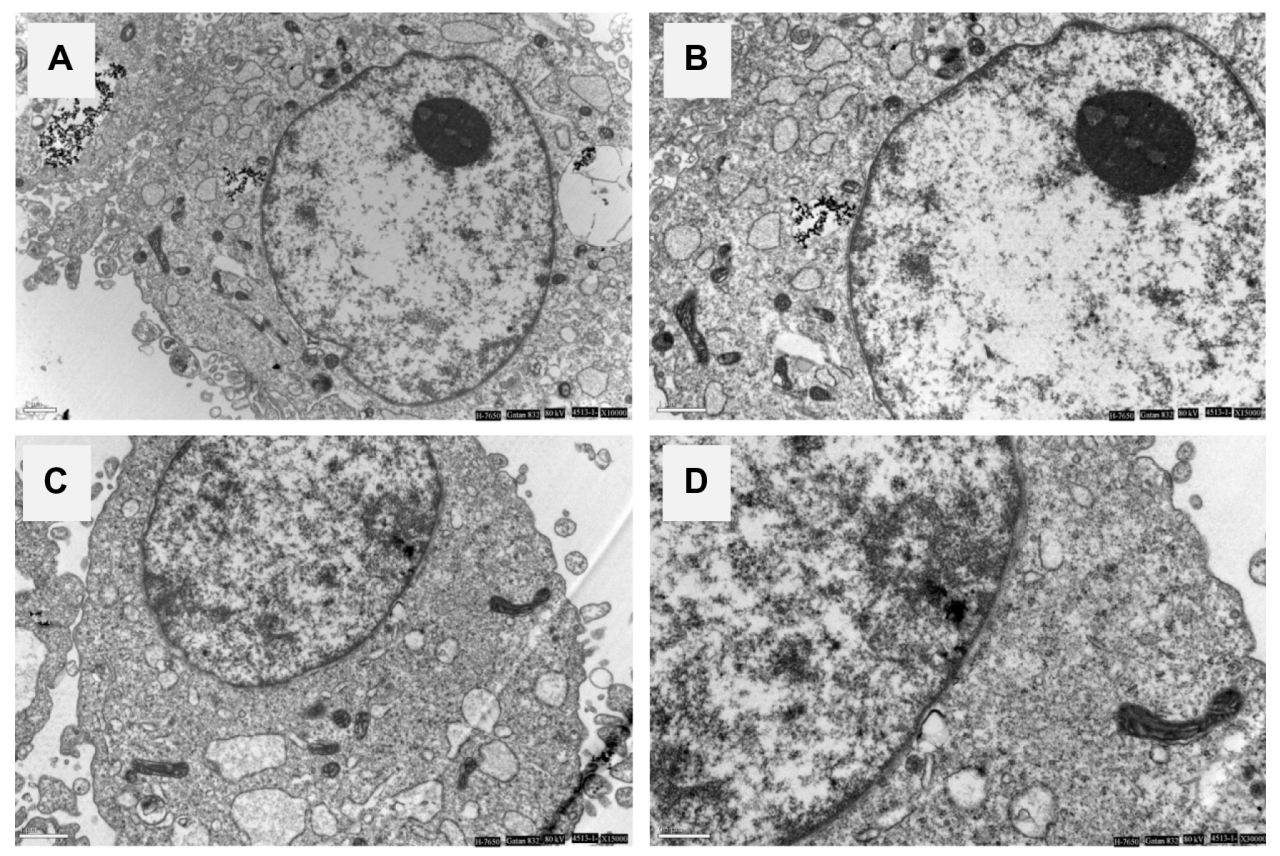

Figure I 2 Dissolution of rod apatite (A) and needle apatite (C) in MG-63 cell lysosomes. After phagocytosis, the crystals are scattered and retain their original size and shape within phagosomes. Rod apatite is compacted tightly and a proportion of the crystals begin to dissolve. Images (B) and (D) are close-up observations.

and growth of rod-like crystals are constrained by the highly active apatite particle surface in the initial precipitate. ${ }^{8}$ Specifically, driven by hydrothermal pressure, multiple apatite particles are bonded together along the $\mathrm{C}$ axis and convert into rod-like crystals. ${ }^{7,18}$ The temperature of the hydrothermal treatment provides further activation of the particle surface to enable ion exchange and crystal rearrangement among the particles.

There are three key factors in hydrothermal treatment, ie, temperature, pressure, and the aging time of the initial precipitate. Regardless of the hydrothermal treatment conditions, aging time can have a significant impact. ${ }^{19}$ For hydrothermal treatment of apatite precipitate at $70^{\circ} \mathrm{C}$ after aging for 2 months, only very small crystals were formed. This is because the apatite precipitates have already started to grow along the $\mathrm{C}$ axis even before hydrothermal treatment. However, the aging process reduced the surface energy of the particles and thus reduces the area of high energy surface..$^{20}$ The freshly prepared apatite precipitate has high surface reaction activity which is significantly decreased after aging, indicating that aging time can markedly affect the growth of nanoapatite crystal. Under the same hydrothermal treatment conditions, fresh apatite precipitate gives notably larger crystals than the aged apatite precipitate.

In this study, the synthesized nanoapatite crystals were needle-like or rod-like and showed a similar degree of crystallinity compared with bone apatite crystals. The nanoapatite crystals consisted of hydroxyapatite and contain ions such as $\mathrm{OH}^{-}, \mathrm{CO}_{3}{ }^{2-}$, and $\mathrm{HPO}_{4}{ }^{2-}$. Hydrothermally treated nanocalcium phosphate needles are similar to the natural apatite microcrystals with regard to morphology, crystal structure, crystallinity, and composition, which could be potentially helpful for making bone substitutes in the future. ${ }^{21,22}$

We used nanoapatite crystals with different morphology and properties to investigate the effects of apatite on cell responses. Synthetic nanoapatite is usually used as an implant biomaterial for the surgical treatment of bone defects, so the osteoblast-like MG-63 cell was selected as the model to study the biological properties of nanoapatite.

Results of an MTT assay showed that both rod-like and needle-like apatite crystals could promote the viability of MG-63 cells with time, indicating that apatite had good cytocompatibility. After 3 days of culture, no obvious difference in optical density was found for MG-63 cells between rod-like and needle-like apatite crystals. However, after 5 days, it was observed that the optical density for rod-like apatite was obviously higher than for needle-like apatite crystals, indicating that rod-like apatite promoted more cell proliferation than needle-like apatite.

TEM observation was used to investigate whether the rod-like and needle-like apatite crystals could enter into cells. The results showed that both the rod-like and needle-like apatite crystals had entered into cells, were close to the nuclear envelope, and did not enter into the nucleus. Our study 
demonstrates that apatite crystals with different properties, when interacting with osteoblast-like MG-63 cells, can trigger different biological effects, especially in osteoblastic proliferation and osteoblastic microstructure.

\section{Conclusion}

The conditions of hydrothermal treatment markedly affected the crystallinity, morphology, and size of the nanoapatite crystals prepared in this study. High crystallinity and large crystal size were obtained at higher hydrothermal temperatures and longer hydrothermal treatment times. The nanoapatite crystals were needle-like in shape when prepared at ambient pressure and were rod-like when prepared under increased pressure. The aging time of the initial hydroxyapatite precipitate significantly affected growth of the nanoapatite crystals. Under the same hydrothermal treatment conditions, fresh hydroxyapatite precipitate gave notably larger crystals than aged hydroxyapatite precipitate. Our results demonstrate that rod-like apatite crystals can promote cell proliferation. Furthermore, it was found that a good deal of needle-like apatite entered into cells and had obvious effects on cell morphology, as reflected in changes in the cell cytoskeleton. In conclusion, rod-like apatite was more conducive to proliferation of osteoblast MG-63 cells than needle-like apatite crystals.

\section{Acknowledgments}

This study was supported by grants from the Major Program of Natural Science Foundation of Shanghai, China (11JC1416302) and the National Natural Science Foundation of China (81000813).

\section{Disclosure}

The authors report no conflicts of interest in this work.

\section{References}

1. Tadic D, Epple M. A thorough physicochemical characterization of 14 calcium phosphate-based bone substitution materials in comparison to natural bone. Biomaterials. 2004;25(6):987-994.

2. Kikuchi M, Itoh S, Ichinose S, et al. Self-organization mechanism in a bone-like hydroxyapatite/collagen nanocomposite synthesized in vitro and its biological reaction in vivo. Biomaterials. 2001;22(13):1705-1711.
3. Zhou H, Lee J. Nanoscale hydroxyapatite particles for bone tissue engineering. Acta Biomater. 2011;7(7):2769-2781.

4. Nuzzo S, Meneghini C, Braillon P, et al. Microarchitectural and physical changes during fetal growth in human vertebral bone. J Bone Miner Res. 2003;18(4):760-768.

5. Aoki H. Science and Medical Application of Hydroxyapatite. Tokyo, Japan: Japanese Association of Apatite Science. 1991.

6. Neira IS, Kolenko YV, Lebedev OI, et al. An effective morphology control of hydroxyapatite crystals via hydrothermal synthesis. Cryst Growth Des. 2009;9(1):466-474.

7. Zhang X, Vecchio KS. Hydrothermal synthesis of hydroxyapatite rods. J Cryst Growth. 2007;308(1):133-140.

8. Liu JB, Ye XY, Wang $\mathrm{H}$, et al. The influence of $\mathrm{pH}$ and temperature on the morphology of hydroxyapatite synthesized by hydrothermal method. Ceram Int. 2003;29(6):629-633.

9. Deng XM, Hao JY, Wang CS. Preparation and mechanical properties of nanocomposites of poly(d,1-lactide) with Ca-deficient hydroxyapatite nano crystals. Biomaterials. 2001;22(21):2867-2873.

10. Dorozhkin SV. Nanosized and nanocrystalline calcium orthophosphates. Acta Biomater. 2010;6(3):715-734.

11. Vasilea E, Popescub LM, Piticescu RM, et al. Physicochemical and biocompatible properties of hydroxyapatite based composites prepared by an innovative synthesis route. Mater Lett. 2012;79(15):85-88.

12. Shi ZL, Huang X, Cai YR, et al. Size effect of hydroxyapatite nanoparticles on proliferation and apoptosis of osteoblast-like cells. Acta Biomater. 2009;5(1):338-345.

13. Okada S, Ito H, Nagai A, et al. Adhesion of osteoblast-like cells on nanostructured hydroxyapatite. Acta Biomater. 2010;6(2):591-597.

14. Pleshko N, Boskey A, Mendelsohn R. Novel infrared spectroscopic method for the determination of crystallinity of hydroxyapatite minerals. Biophys J. 1991;60(4):786-793.

15. Watanabe T, Kawachig G, Kamitakahara M, et al. Formation of needlelike hydroxyapatite by hydrothermal treatment of $\mathrm{CaHPO}_{4} \cdot 2 \mathrm{H}_{2} \mathrm{O}$ combined with $\beta-\mathrm{Ca}_{3}\left(\mathrm{PO}_{4}\right)_{2}$. Journal of the Ceramic Society of Japan. 2009;117(1366):759-764.

16. Panda RN, Hsieh MF, Chung RJ, et al. FTIR, XRD, SEM and solid state NMR investigations of carbonate-containing hydroxyapatite nanoparticles synthesized by hydroxide-gel technique. J Phys Chem Solids. 2003;64(2):193-199.

17. Liou SC, Chen SY, Liu DM. Synthesis and characterization of needlelike apatite nanocomposite with controlled aspect ratios. Biomaterials. 2003;24(22):3981-3988.

18. Sorrell CC, Ben-Nissan B. Hydrothermal synthesis and characterization of fine apatite crystals. Mater Sci Forum. 1991;371:34-36.

19. Feng W, Mu-sena L, Yu-penga L, et al. A simple sol-gel technique for preparing hydroxyapatite nanopowders. Mater Lett. 2005;59(8-9): 916-919.

20. Kothapalli CR, Wei M, Legeros RZ, et al. Influence of temperature and aging time on HA synthesized by the hydrothermal method. $J$ Mater Sci Mater M. 2005;16(5):441-446.

21. Evis Z, Webster TJ. Nanosize hydroxyapatite: doping with various ions. Advances in Applied Ceramics. 2011;110(5):311-320.

22. Uskokovic V, Uskokovic DP. Nanosized hydroxyapatite and other calcium phosphates: chemistry of formation and application as drug and gene delivery agents. J Biomed Mater Res B Appl Biomater. 2011;96(1):152-191.

\section{Publish your work in this journal}

The International Journal of Nanomedicine is an international, peerreviewed journal focusing on the application of nanotechnology in diagnostics, therapeutics, and drug delivery systems throughout the biomedical field. This journal is indexed on PubMed Central, MedLine, CAS, SciSearch ${ }^{\circledR}$, Current Contents ${ }^{\circledR} /$ Clinical Medicine,
Journal Citation Reports/Science Edition, EMBase, Scopus and the Elsevier Bibliographic databases. The manuscript management system is completely online and includes a very quick and fair peer-review system, which is all easy to use. Visit http://www.dovepress.com/ testimonials.php to read real quotes from published authors. 